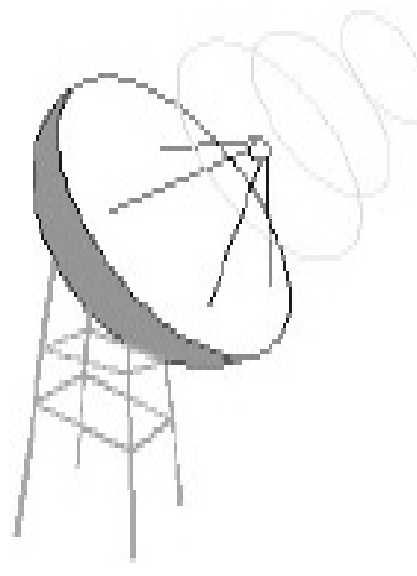

\title{
Hibridações discursivas: Estratégias políticas e mercadológicas dos veículos de comunicação de massa ${ }^{1}$
}

\author{
Discourse hybridation: marketing and political strategies of mass media \\ Maria Berenice da Costa Machado \\ Professora do Curso de Comunicação Social, Doutora em Comunicação Social pela PUCRS. \\ E-mail: mberem@feevale.br
}

Resumo

A partir dos processos de hibridação entre os discursos normativo, jornalístico e publicitário do jornal Zero Hora, no período 1998-2004, e da compreensão de que são estratégicos para a sua ação política e mercadológica, propõem-se fundamentos para futuros estudos das hibridações discursivas dos veículos de comunicação de massa. Considera-se como marca dessas hibridações as contradições entre as orientações do manual de redação e as coberturas jornalísticas, e destas com a comunicação publicitária. A reflexão fundamenta-se teórica e metodologicamente na complexidade do tempo presente, dialoga acerca das relações e das transgressões discursivas de um veículo de comunicação como Zero Hora, e considera, especialmente, a natureza da atividade da imprensa e da propaganda, o mercado editorial e publicitário, bem como a influência política desse diário no Rio Grande do Sul.

Palavras-chave: Mídia, hibridação discursiva, estratégia.

Introdução

Encerrada a campanha eleitoral de 2004, volta a repercutir o comportamento de alguns veículos de comunicação em face de determinadas candidaturas. $\mathrm{Na}$ reportagem "As falsas sutilezas do Jornalismo: medições da cobertura da mídia mostram que a imprensa, ao contrário do que apregoa, tomou partido $^{2}$ em SP", a revista Carta Capital (CC) (27 out. 2004, p. 31) apresenta a análise de dois institutos de pesquisas ligados ao meio acadêmico e argumenta sobre a parcialidade de certos jornais durante as eleições municipais ${ }^{3}$. O Doxa, laboratório do Instituto Universitário de Pesquisas do Rio de Janeiro (Iuperj) que tem como missão estudar a mídia, quantificou e qualificou as menções nos jornais aos candidatos envolvidos na disputa em São Paulo, classificando as reportagens sob três critérios positivas, negativas e neutras - e percebeu "tratamentos diferenciados dispensados aos contendores principalmente quando se comparam os dois primeiros colocados, Marta Suplicy e José Serra (...) de longe, a petista mereceu tratamento bem mais negativo que o tucano". A semelhantes conclusões também chegou o Observatório Brasileiro de Mídia (OBM), ligado à Escola de Comunicações e Artes da Universidade de São Paulo (ECA/ USP) sobre a campanha à Prefeitura de São Paulo. Para a revista $C C$, é difícil explicar tamanha diferença apenas com base em critérios jornalísticos.

Landowski (1992, p.127) orienta a compreensão do papel da mídia no jogo político: o "fazer persuasivo em política se dá no interior de um processo de transformação mais geral, que concerne ao desenvolvimento dos meios de comunicação de massa em seu conjunto". De acordo com o semiólogo, o discurso político se contamina, se regenera ou se rearticula em função da lógica da comunicação midiática, mais especialmente, a publicitária ${ }^{4}$. Nessa mesma direção seguem os estudos desenvolvidos pela autora desde 1998 e que se transformaram na tese de doutorado "Estratégias híbridas de ação política e mercadológica: estudo dos discursos normativo, jornalístico e publicitário do jornal 
Zero Hora, no período 1998-2004" (MACHADO: 2004). Defende-se a hipótese de o diário gaúcho atuar nas suas coberturas eleitorais fazendo propaganda política e de sustentar, com a publicidade, o discurso da "imparcialidade", posição evidenciada mediante análise das suas manchetes de capa; e que as contradições entre tais práticas jornalísticas e a retórica publicitária são estratégicas para as suas relações políticas e mercadológicas. Essas transgressões podem ser particularmente convenientes para Zero Hora $(Z H)$, ou até mesmo necessárias em determinadas ocasiões, mas contrariam os valores e os princípios cultivados pela imprensa (a "verdade" e o interesse público seriam alguns deles). Mesmo assim, o jornal mantém posição destacada no mercado editorial-publicitário nacional e no cenário político local.

As reflexões sobre o comportamento eleitoral da mídia são sazonais e parecem restritas à academia e à parte da imprensa - minoritária - que pratica o jornalismo crítico. Weissheimer (2004) observa que "em períodos eleitorais, um velho fantasma assola a esquerda: o papel manipulador da mídia. Nas derrotas, a gritaria é grande. Passadas as eleições, tudo volta ao normal e velhos vícios e ilusões sobre a relação com a grande mídia realimentam uma tediosa rotina".

Na matéria da Carta Capital há, também, a denúncia de que nem mesmo as críticas feitas durante o período eleitoral e sem vínculos diretos com a esquerda encontram eco: "A Folha de S. Paulo (FSP) parece não levar muito em conta a opinião de seu próprio ombudsman (...)"; cita as últimas eleições municipais, ocasião em que “(...) Marcelo Beraba, por inúmeras vezes, tratou em sua coluna dominical das falhas da cobertura da disputa à Prefeitura paulistana". Como exemplo, cita o dia 19 de setembro, em que o ouvidor conclui que "existe um nítido desequilíbrio no acompanhamento da Prefeitura de São Paulo". A questão levantada pelo jornalista não seria "o rigor que o jornal se impõe na cobertura da administração Marta Suplicy, mas com a inexistência de igual empenho e regularidade na cobertura da administração do governador Geraldo Alckmin" [principal cabo eleitoral de José Serra]. Quase um mês depois, na edição de 13 de outubro, a ineficácia das críticas do ombudsman da FSP fica ainda mais evidente quando o jornal estampa a manchete "Maluf é indiciado pela PF e declara seu apoio a Marta" (CC, 27 out. 2004, p. 31).

Carta Capital classifica as matérias como "falsas sutilezas de um jornalismo supostamente objetivo" e defende que as críticas dirigidas à $F S P$ poderiam ser estendidas a outros jornais. Considerando que em breve se instalará um novo processo de disputas e coberturas eleitorais, este artigo deseja antecipar o debate e contribuir para o aperfeiçoamento dos campos da Comunicação e da Política. A partir do caso do jornal $\mathrm{ZH}$, propõem-se fundamentos para futuras análises do comportamento eleitoral dos veículos de comunicação de massa.

Falta transparência à mídia

Entende-se que parte das questões que se levantam em relação à mídia e às suas coberturas eleitorais está na resistência da imprensa em manifestar posição clara e objetiva a favor de seus candidatos, partidos e ideologias, em espaços editoriais. $\mathrm{Na}$ mesma reportagem, a revista Carta Capital observa que "entre as boas tradições do jornalismo 
dos Estados Unidos [acrescentese, também adotada por alguns jornais europeus, que anunciam em editoriais seus candidatos e partidos, procurando manter o equilíbrio no noticiário], raramente copiadas pela imprensa brasileira, está o hábito de informar aos leitores, em editorial, o candidato de preferência dos acionistas da publicação. E não apenas em eleições presidenciais" (CC, 27 out. 2004, p. 31).

O jornal gaúcho $Z H$ segue a tendência nacional, conforme se constata na análise das suas coberturas eleitorais nas campanhas para o governo do Estado do Rio Grande do Sul (RS) em 1998 e no ano 2002, e para a prefeitura de Porto Alegre durante o pleito de 2000 (MACHADO: 2004). Exceções são Carta Capital (Lula) e O Estado de S. Paulo (José Serra) durante as eleições presidenciais brasileiras de 2002, que "declararam em editorial preferência por um dos candidatos em disputa", enquanto os demais veículos adotaram métodos "mais subliminares de expressar suas convicções" (CC, 27 out. 2004, p. 31). Um dos possíveis "métodos subliminares" de a mídia "expressar" suas convicções é o processo de hibridação entre os seus discursos, ou seja, sustentar a contradição entre seus códigos normativos, as práticas jornalísticas e a autopublicidade.

Para Marcus Figueiredo, coordenador do Doxa, não há nada de errado em um veículo se posicionar: "É sempre melhor deixar as coisas claras, informar os leitores, do que esconder uma opção sob o manto da imparcialidade" (CC, 27 out. 2004, p. 31). Concorda-se, em parte, com a posição do pesquisador; as razões pelas quais a mídia brasileira não toma posição político-partidária eleitoral clara é estratégica, visando "preservar" suas relações mercadológicas com anunciantes e leitores- ouvintes-telespectadores. Assim, o que "impede" a mídia de tomar partido de maneira transparente não são os princípios jornalísticos, pregados e apregoados nos manuais de redação e ética, mas seus interesses comerciais que visam agradar leitores-audência, vender assinaturas ou exemplares avulsos e, conseqüentemente, usar tais índices na ocasião em que vendem seus espaços publicitários para anunciantes e agências de publicidade, estes, sim, os verdadeiros responsáveis pela saúde e sobrevivência financeira dos monopólios privados da mídia brasileira.

$\mathrm{Na}$ defesa dos interesses mercadológicos, a postura da mídia expõe, ainda, suas estratégicas políticas e são obstáculos à democracia. Sader (2004) manifestase sobre a postura da mídia na campanha de 2004: “(...) a mais vergonhosa cobertura da imprensa escrita desde a ditadura. Uma aliança férrea entre os dois maiores jornais, em que todos os editores envolvidos e os colunistas, praticamente sem exceção, se alinharam ao candidato da coligação PSDB/PFL, fez desses órgãos veículos de campanha desse candidato, falseando a informação e fabricando um consenso antidemocrático que atenta abertamente contra a democracia". O sociólogo entende que "terminou a censura externa, passando os proprietários privados desses meios a usar, conforme seus interesses e critérios, os espaços de expressão de seus jornais e televisões. Uma liberdade condicionada pelo filtro de meios de comunicação diretamente dependentes das agências de publicidade e das empresas que costumam anunciar (...)". Sader comenta também que a pesquisa do OBM "demonstrou inequivocamente como a cobertura dos dois maiores jornais favorece o candidato que apóiam, sem que 
nenhuma tentativa de responder a esses argumentos fosse sequer esboçada pelos seus proprietários, demonstrando um silêncio que concorda com as acusações (...)".

Se há silêncio e faltam respostas às acusações dos que refletem sobre as coberturas da mídia, há ocasiões em que os senhores do jornalismo brasileiro corroboram com a crítica. Ao avaliar a campanha eleitoral para o governo do RS, em 1998, o vice-presidente da RBS, Fernando Ernesto Correa, admite a associação da empresa ao projeto de Antônio Britto, e não ao de Olívio Dutra. A isenção do jornalismo, um dos valores da RBS, é negada por Correa: "Essa isenção que dizem da gente é bobagem. Ninguém é isento nem imparcial. O fato de noticiar ou não já é uma decisão" (apud BUENO, 1999, p.56-58). Outro exemplo é o discurso de agradecimento do jornalista Ruy Mesquita, editor d'O Estado de São Paulo, ao receber o prêmio "Personalidade de Comuni-cação de 2004", em que faz referência à "murdoquização" dos meios de comunicação, "ameaçando a qualidade do jornalismo por subordinar sua cobertura aos interesses do departamento financeiro" (apud LONGOBARDI: s/d).

\section{As condições discursivas}

Encontra-se na configuração do tempo presente - chamado de contemporaneidade ${ }^{5}$ por Baudrillard, Coelho Netto, Rubim; ou de pósmodernidade, expressão usada por Heller, Lyotard, Connor, Harvey - e, mais especificamente, sobre a sua marca preponderante, a complexidade $^{6}$ - compreensão a partir de Morin -, parte das condições dos acontecimentos discursivos de $Z H$, considerando que a complexidade permeia grande parte das relações e dos processos sociopolíticos.
As redes da comunicação, nas quais se insere o jornal gaúcho, são seus melhores exemplos: suas instantanei-dade e velocidade alteraram definitivamente a noção de espaço e de tempo. A tecnologia e a revolução digital desencadearam rupturas, quebras e mudanças de paradigmas; há sobreposições, colagens, mosaicos, pastiches e misturas em todos os campos da vida social. O resultado são os híbridos $^{7}$, denomi-nação apropriada da experiência científica de cruzar dois ou mais elementos, adaptada à cultura por Canclini e à comunicação por Weber ${ }^{8}$.

A complexidade e a dinâmica da hibridação entre os acontecimentos discursivos de $Z H$ estão ligadas, também, aos jogos de poder e de visibilidade disputados e pactuados entre a Sociedade, a Política e a Mídia ${ }^{9}$ Em uma sociedade democrática como a brasileira, o poder, em tese, seria o dos sujeitos sociais, pela capacidade que têm de pensar e de se organizar em grupos, de agir, de opinar, de votar, de produzir e de consumir, em massa, poderes e paixões, bens e serviços. No entanto, o poder dos sujeitos está assujeitado ao poder do mercado. A comunicação integra as redes de poder e medeia interesses: tudo vê e faz ver com agilidade, articula movimentos políticos, fatos e sujeitos, fomenta paixões, seduz, dá visibilidade, alavanca a economia capitalista ${ }^{10}$.

Zero Hora é sujeito ${ }^{11}$ midiático e, assim sendo, atua também nos campos econômico, social e político, amparado pela credibilidade da opinião pública, dos leitores - avulsos e assinantes - e dos anunciantes. Em um ambiente cada vez mais competitivo, o jornal de 41 anos se mantém, há mais de 20 , como o principal diário impresso do Rio Grande do Sul; pertence à Rede Brasil Sul, maior grupo de
5 Contemporaneidade aquilo que é do tempo vivido - uma complexa e tensa convergência de espaços geográficos e virtuais, convivências e televivências, local e global, nas quis "uma teoria, uma visão de mundo não supera outra, convive com ela" (Coelho Netto, s.d., p.37). Nestas super-posições - ou hibridações - que configuram o tempo presente, a centralidade da comunicação, a indeterminação, a diversidade, a pluralidade dos centros de poder tecem o cenário dos acontecimentos discursivos de Zero Hora.

6 A opção pela complexidade (considerando complexo o que se tece junto) para orientar este percurso teórico-metodológico tem relação com a sua possibilidade de "ordenar/ desordenar/ organizar" empiricamente fenômenos desordenados e contradi-tórios, tais quais encontram-se os discursos de $Z H$ (MORIN 2001a, p.91, 93, 94 e 99 ).

${ }^{7}$ A hibridação, como processo característico da sociedade contempo-rânea, está presente em todos os seus campos e relações (Weber, 2000b). Fausto Neto (1991) observa que o híbrido é complexo; assim, torna-se uma das marcas culturais deste tempo, fruto do pluralismo, da miscigenação, do cruzamento, da mistura de pelo menos duas espécies diferentes.

${ }^{8}$ Canclini (1990) estuda as culturas híbridas, geradas ou promovidas pelas novas tecnologias comunicacionais, pela reorganização do público e do privado no espaço urbano e pela desterritorialização dos processos simbólicos, geradoras de poderes oblíquos.

As estratégias híbridas na área da comunicação são constituídas por Weber (2000b). A partir dos "termos calvinos" visibilidade, leveza, rapidez, 
exatidão, multiplicidade e consistência, aos quais a pesquisadora acrescenta ética e cinismo, une palavras opostas e chega ao processo de hibridação publicidade, velocidade, densidade, organicidade, igualdade, totalidade e moralidade. Três dessas estratégias publicidade, junção entre a visibilidade e a opacidade; igualdade, resultado da junção entre multiplicidade e unicidade; e moralidade, que reúne a ética e o cinismo - são articuladas com a análise dos discursos de ZH e, posteriormente, cruzadas entre si nas "estratégias híbridas de ação política e mercadológica".

${ }^{9}$ Morin (1995) compreende que a política foi permeando por todos os poros da sociedade, ao mesmo tempo em que se deixava penetrar por todos os problemas da sociedade. Nada escapa à política, todas as atividades associadas, de algum modo, à esfera institucional política, e o espaço onde se realizam são políticas. Assim, a política se alimenta do jogo que as pessoas disputam entre si; no vencer, ou seja, na vitória, o político encontra sua própria condição de sobrevivência como ser político (SARTORI: 1997). Champagne (1996, p.24) relaciona o jogo político à luta simbólica, "na qual cada ator político procura monopolizar a palavra pública ou, pelo menos, fazer triunfar sua visão do mundo e impô-la como visão correta ou verdadeira [...]".

${ }^{10}$ Para Berger (1998, p.22), o atual poder da comunicação nas sociedades contemporâneas está ligado ao poder comunicação multimídia do Sul do país, que é afiliado à Rede Globo, primeiro conglomerado de mídia brasileiro e dos maiores do planeta.

A orientação do Grupo RBS aos seus veículos é voltada para a vanguarda tecnológica, em sintonia com o mercado consumidor/leitor, e patrocinador/anunciante. $\mathrm{O}$ conceito de atualidade, exacerbado pela revolução digital, se constitui mais uma questão delicada e complexa para os jornais impressos, pois vai de encontro à natureza desses veículos. Para compensar o hiato entre o fato, sua apuração, edição, impressão, circulação e leitura, diários como $Z H$ empreendem esforços em direção às redes mundo-digitais da informaçãocomunicação, pois são elas que lhes garantem acesso às fontes, possibilitam edições on-line, onde os conteúdos são freqüentemente atualizados.

Se atrativa do ponto de vista tecnológico, a versão digital ainda não garante o faturamento de um jornal como $\mathrm{ZH}$; sua sobrevivência vem da comercialização e veiculação de espaços publicitários na edição impressa, a mesma que será oferecida aos leitores avulsos e aos assinantes. Rüdiger (1998, p.8387) observa que "o Grupo RBS desenvolveu novos métodos de gestão empresarial em seus veículos, baseando seus negócios na renovação tecnológica de suas instalações e na qualificação mercadológica de seus respectivos produtos". Para o autor, predomina amplamente nos projetos jornalís-ticos da RBS a racionalidade mercadológica e a política monopo-lista de ocupação de todos os seus espaços, o que não exclui necessaria-mente critérios de qualidade editorial. O Grupo RBS procede a uma integração vertical dos mercados em que atua, de modo que caiba aos veículos da empresa o controle, senão da esfera pública midiada, pelo menos das principais fontes de patrocínio publicitário. Para alcançar a atual posição de liderança no mercado editorial, $\mathrm{ZH}$ se submete a inúmeras transformações, mudanças gráficas e editoriais, inovações técnicas e comerciais; o jornal credita tais alterações à preocupação de atender aos interesses dos seus leitores, "sem abrir mão de seus compromissos com o público, com o país e com a verdade" ${ }^{12}$ (Zero Hora, 4 mai. 1994, p.3-5).

O tablóide Zero Hora se insere no atual cenário midiático, político e social - global e local - e tem a preferência do mercado anunciante, por ser o diário com o maior número de leitores no Estado e um dos dez maiores do Brasil. A circulação da sua edição impressa concentra-se na região Sul, mas a versão digital rompe os limites geográfico-temporais, estando disponível e acessível na Internet para leitura e consulta, nos quatro cantos do mundo. O conteúdo de $Z H$ é referência e pauta para outros veículos de comunicação: as rádios locais, inclusive as da RBS, mantêm o hábito de ler as notícias do jornal no ar. Fato semelhante ocorre com outros periódicos do interior do $\mathrm{RS}$, para os quais $Z H$ é padrão e, não raro, fonte de informação. O efeito multiplicador, agendando outros veículos de comunicação, amplia a importância e a responsabilidade social do diário da RBS, liderança que o coloca no centro dos acontecimentos político-mercadológicos: as coberturas jornalísticas e os anúncios veiculados em $Z H$ impactam parcela considerável da sociedade sul-rio-grandense.

Corroboram também com tais condições discursivas, as singularidades sociais e políticas do RS: o Estado tem o menor índice de analfabetismo do Brasil e o maior potencial de leitores, o que 
explica o elevado percentual de consumo de jornais. Os gaúchos, tradicional-mente, participam das disputas eleitorais, e estas passam pela imprensa; assim, a seção de política é das mais lidas, conforme observou a editora de política de $\mathrm{ZH}$, jornalista Rosane de Oliveira (2003). As polêmicas geradas pelas matérias sobre as eleições acabam atraindo mais leitores/eleitores, aumentam as tiragens, os anúncios e o faturamento do jornal. Essa dinâmica até pode ser conveniente para $Z H$, desde que não comprometa a sua credibilidade entre a opinião pública, pois, como observou Berger (1998), a credibilidade é questão vital para o sucesso do empreendimento jornal; é o "capital simbólico" que qualifica a imprensa no exercício das funções políticas pertinentes à sua natureza, informar e servir ao interesse público, mas não a habilita como sujeito em outros campos. É vetado à imprensa agir, a partir dos seus domínios jornalísticos, "votar" a favor de determinado partido ou candidato. $\mathrm{O}$ espaço para tais manifestações é o editorial território livre para os interesses e opiniões da empresa $(Z H$, além do espaço editorial, possui a coluna "Opinião").

\section{A cena discursiva}

Em 1998, Antonio Britto, ex-jornalista da RBS, postula a reeleição como governador do RS, mas é derrotado por Olívio Dutra, do Partido dos Trabalhadores (PT). O acontecimento aumenta a instabilidade político-mercadológica vivida pelo Grupo controlador do jornal $\mathrm{ZH}$ e contribui para a chamada "Crise de 1998", iniciada em junho daquele ano, e que foi "das maiores já vivida pela RBS" (SCHIRMER: 2002, p.184-85). Após o leilão de privatização das empresas nacionais de telefonia, o Grupo rompe o consórcio com a Telefónica, da Espanha, enxuga seu quadro de pessoal, suspende investimentos, vende sua parte na BCP de São Paulo (consórcio para a telefonia celular, no qual a RBS estava associada à Bell South e ao Banco Safra), a NET Sul (operação de televisão por cabo) e o ZAZ, provedor de Internet. Zero Hora inicia um processo de reposicionamento da sua imagem perante a opinião pública. A primeira atitude, após o encerramento da campanha eleitoral, foi colocar $A s$ pesquisas em seu devido lugar: em coluna assinada por Marcelo Rech (1998), diretor de redação de $Z H$, o diário da RBS promete que as sondagens passarão a ser "acessórios nas futuras coberturas eleitorais".

Pesquisas encomendadas pela RBS, no início de 1999, refletem a imagem de $Z H$ entre a opinião pública: o diário "estava sendo percebido como um jornal que não era imparcial, não mostrava os dois lados, não tinha contraponto, atrelado a uma certa visão liberal, associado a governos anteriores" (FIRPO; PINO; KINDLEIN, 1999). O fato inequívoco é que o periódico posicionava-se na contramão da maioria do eleitorado gaúcho que no ano anterior "oPTara" pelo governo de esquerda para o estado do RS. Tais questões de natureza política pressionam o mercado editorial-publicitário: opor-se ao PT significa, para $Z H$, contrariar a parte dos seus leitores e anunciantes que são, simultaneamente, eleitores do partido. O periódico ficara, também, sem os anúncios do Governo do Estado, um dos seus principais patrocinadores que, em processo de licitação para as agências de publicidade, esteve praticamente fora da mídia naquele ano.

Todos esses são fatores motivadores para as reformulações na
${ }^{12}$ Sobre a relação discurso-poder, Eco (2001, p.58) compreende o jornalismo como instrumento de poder, poder este originado pelos discursos que produz e torna visíveis no campo sociopolítico. Os jornais são "administrados por partidos ou grupos econômicos que usam uma linguagem voluntariamente crítica, pois sua verdadeira função não é dar notícias aos cidadãos, mas enviar mensagens cifradas a um outro grupo de poder passando por cima da cabeça dos leitores. 
comunicação institucional de $Z H$. Assim, aproveitando o aniversário de 35 anos, em maio de 1999, o jornal veicula campanha publicitária, altera seu slogan e passa a afirmar ter "Compromisso com a inteligência do leitor". O compromisso é breve: $\mathrm{ZH}$ muda de agência de publicidade e, em outubro, faz nova investida publicitária para lançar o slogan "A vida por todos os lados", que desde então aparece com a assinatura do jornal. À mesma época, a RBS celebra um convênio com o CEPA/ UFRGS - Centro de Estudos e Pesquisas em Administração da Universidade Federal do Rio Grande do Sul. Os resultados das investigações mercadológicas e eleitorais feitas pelo instituto passam a ser publicados nos veículos do Grupo. $\mathrm{O}$ aval da maior instituição pública de ensino superior do RS convém à imagem da RBS e dos seus veículos.

No final de 1999, um ano antes das eleições, $Z H$ começa a publicar as primeiras pesquisas IBOPE e CEPA/UFRGS com as intenções de voto para a prefeitura da capital do RS e das principais cidades do interior. Na capa do jornal, as manchetes secundárias não destacam nomes nem números, apenas indicam a realização da pesquisa e chamam para a cobertura no miolo da edição. A primeira sondagem está acompanhada da Carta ao Leitor, Pesquisa e independência, assinada por Rech (1999), que ratifica a coluna anterior: “(...) $\mathrm{ZH}$ anunciou em novembro passado que deixaria de conferir caráter de manchete às pesquisas eleitorais, embora continuasse a publicá-las por considerá-las um elemento a mais na informação política."

As eleições municipais de 2000 são mais um capítulo do complexo diálogo entre $Z H$ e as disputas eleitorais: para cumprir a promessa de não destacar os resultados de pesquisas na capa, o diário desloca a cobertura para o caderno especial Eleições 2000 e mantém igual rigor na primeira página daquele suplemento. Zero Hora altera a estratégia, mas não se isola do processo eleitoral: em plena vigência do seu novo slogan, o jornal não mostra a eleição, que faz parte da vida, por todos os lados: ao contrário, polariza a disputa desde o primeiro - e plural - turno entre os nomes de Tarso Genro (PT) e Alceu Collares (PDT), e privilegia, nas capas do caderno eleitoral, os pontos polêmicos e os supostos problemas da capital do RS. As manchetes de $Z H$, na ocasião, são idênticas aos argumentos dos candidatos de oposição ao Partido dos Trabalhadores, que administrava a cidade havia 12 anos: obras, trânsito, emprego, saúde, violência, moradia, educação. E não há contraponto, ou seja, não é possível ver naqueles mesmos espaços de $\mathrm{ZH}$ a vida pelo outro lado.

Aagenda 2001 nãoprevêeleições, mas as pesquisas publicadas por $Z H$, ao longo daquele ano, indicam o desejo do jornal em pautar o tema, antecipando, assim, a disputa ao governo gaúcho. O diário vai além e, dezoito meses antes da eleição, concentra a corrida ao Piratini em torno do nome de dois virtuais candidatos: Britto, então filiado ao PMDB, e Tarso Genro, postulante às prévias do $\mathrm{PT}$.

No ano eleitoral 2002, $Z H$ volta a publicar os resultados das sondagens de intenção de voto na capa do jornal. Tais prognósticos são manchetes secundárias, talvez para honrar a promessa de Rech (1998) feita quatro anos antes: as pesquisas têm agora "aspecto francamente coadjuvante" na cobertura. Mas a página um de $Z H$, especialmente a das edições dominicais, passa, então, a ter uma aparência híbrida, 
um mosaico onde todos os elementos estão relativizados: as enquetes eleitorais, com os nomes dos primeiros colocados e seus respectivos números percentuais, disputam a atenção do leitor com as demais manchetes - principal e secundárias -, as linhas de apoio e seus pequenos textos, as fotos, as legendas, os selos, a própria identificação do diário e os anúncios publicitários. Se a capa amplia a visibilidade dos elementos nela impressos, faz com que sejam vistos e lidos antes dos demais, a quantidade de componentes, as cores, as fontes e os boxes dificultam as suas distinções hierárquicas, ou seja, transformam as pesquisas eleitorais em "instrumentos acessórios".

Os discurso de $\mathrm{ZH}$ e o percurso metodológico

Com a cena sócio-histórica, faz-se a análise do jornal $Z H$, que, como todo veículo de comunicação, é constituído por uma pluralidade de discursos ${ }^{13}$. Três desses discursos amostras representativas do período 1998-2004 - são o objeto do diálogo da tese. O primeiro discurso é o normativo, de caráter interno, cuja função é orientar a atividade dos jornalistas, escrito a partir dos cânones da imprensa e dos valores traçados pela empresa proprietária (no caso a RBS). O segundo, o discurso jornalístico, corresponde à sua práxis, são matérias e coberturas de acontecimentos que passam pelo processo de apuração-edição, são impressas e circulam nos milhares de exemplares que chegam até o público leitor. O terceiro é o discurso publicitário, igualmente de caráter público, que dá visibilidade à imagem institucional do jornal e à sua promoção comercial.

A priori, o código normativo prescinde de ser publicizado, pois está implícito e, assim, expresso na prática cotidiana do jornal. $\mathrm{O}$ que se observa em $Z H$, no entanto, é o discurso normativo sustentar a argumentação publicitária do diário, especialmente nas ocasiões em que o discurso jornalístico transgride algumas das normas ou princípios dos veículos da RBS, que orienta seus jornalistas a "informar com isenção, responsabilidade e independência; ter como motivação a precisão e o equilíbrio; abrir espaço a todos os lados envolvidos no assunto, sem qualquer preconceito, favorecimento ou perseguição; conferir a veracidade de informações que possam produzir controvérsias; apurar a verdade, com isenção e abrangência" (Zero Hora: 1994, p.9, 13,17 e 19).

Importa destacar que o discurso normativo é extraído de publicações de caráter público que veiculam a imagem que os dirigentes idealizam para o jornal. Isso, no entanto, não elimina a possibilidade de que existam códigos internos, informais e até velados, que ordenam a prática cotidiana de $Z H$. Assim, nas coberturas jornalísticas, durante as eleições de 1998, 2000 e 2002, buscam-se operadores de enunciação ligados à função de persuasão (nomes de candidatos, números e percentuais de intenções de votos, palavras associadas aos sujeitos) para confrontá-los com o código normativo. Mesmo que as manchetes de capa de $Z H$ só divulguem resultados de pesquisas eleitorais ${ }^{14}$, constata-se a presença de elementos com função persuasiva, reveladores da falta de equilíbrio e da parcialidade de $Z H$, que não abre espaços para todos os lados. A (dis)função no texto jornalístico indica ação propagandística em prol de algum candidato ou partido, contrariando o discurso oficial do jornal, que apregoa neutralidade e isenção. A repercussão na sociedade e nos meios políticos
${ }^{13}$ Landowski (1992, p.118) compreende a pluralidade discursiva do jornal como ligada à "diversidade de abordagens, que podem dizer respeito tanto aos conteúdos ideológicos, como às estruturas narrativas ou às estratégias de discurso que aí se manifestam". Discurso, segundo Orlandi (2002, p.15), "tem em si a idéia de curso, de percurso, de correr por, de movimento. 0 discurso é assim palavra em movimento, prática de linguagem [...]". Como objeto sócio-histórico, o discurso é o principal produto e 0 resultado final do funcionamento das mídias; os discursos midiáticos são, em realidade, discursos que se constroem sobre outros discursos. Assim sendo, a compreensão do material empírico de ZH é auxiliada pela Análise de Discurso (AD), ferramenta aberta e compatível com os princípios e a metodologia da Complexidade.

${ }^{14}$ Pesquisas eleitorais são realizadas por terceiros - no caso de ZH, os institutos Ibope, Datafolha e Cepa/ UFRGS - e consideradas discurso científico. 
${ }^{15}$ A (atu)ação das "máquinas vivas" - Zero Hora é uma delas - possibilita transitar e ocupar funções políticas que ultrapassam as suas fronteiras e, às vezes, até a sua própria natureza. Tal fenômeno Morin (1995, p.93) denomina "estratégia" e diz ser essa a diferença entre a máquina viva e a artificial; esta só é capaz de agir a partir de uma programação, enquanto a máquina viva é "capaz de estratégia, ou seja, de inventar seus comportamentos na incerteza e na eventualidade".

Mouillaud (1997) emprega o termo "estratégias" para designar a maneira como certos jornais brasileiros trataram esse ou aquele acontecimento político, esse ou aquele fenômeno cultural.

${ }^{16}$ As estratégias ligadas ao mercado de produção e circulação de produtos e serviços situam-se no campo do marketing, compreendido por Kotler (2000) como um processo social e gerencial pelo qual indivíduos e grupos obtêm o que eles necessitam e querem, através da criação e troca de produtos, serviços, idéias e valores com outros.

${ }^{17}$ As hibridações discursivas não são um fenômeno particular de ZH ou um caso restrito ao jornalismo brasileiro. Ao acompanhar a cobertura jornalística durante uma campanha eleitoral presidencial na Espanha, Sampedro (1999) encontrou um processo de hibridação, que denominou info-propaganda, ou seja, informação gráfica eleitoral, resultado da capacidade dos meios de transformar a propaganda em informação. A razão, segundo o autor, é que este "tipo" de informação eleitoral resulta 1,5 vezes mais crivel que a publicidade equivalente. coloca em xeque a credibilidade e a independência do jornal. Mas $\mathrm{ZH}$ reage e, rapidamente, ratifica seus princípios normativos nos espaços editoriais e em campanhas publici-tárias: propaga $a$ imagem institucional idealizada para o jornal que, necessariamente, não é a mesma percebida pela sociedade-políticos, leitores, anunciantes e opinião pública.

Analisa-se, então, o discurso publicitário de Zero Hora, através das campanhas e promoções desenvolvidas em 1999, ano intermediário às eleições de 1998 e 2000, e momento de reconfiguração das forças políticas do Estado. Importa destacar que Zero Hora estava sendo percebido como um jornal de oposição à administração petista que governava o RS. O clima após a campanha eleitoral - confirmado pela pesquisa encomen-dada pela RBS - motiva o reposicionamento da comunicação publicitária do periódico. Assim, desde outubro daquele ano, o slogan institucional argumenta que Zero Hora é um jornal que mostra "A vida por todos os lados". Na comunicação publicitária de $Z H$ distinguem-se os argumentos, as escolhas lexicais e as assertivas, visando ligá-las aos acontecimentos eleitorais de 1998 e às coberturas das eleições $2000 \mathrm{e}$ 2002. Sobre estas últimas disputas, a intenção é verificar o cumprimento do proposto no novo slogan institucional do jornal, elencando os nomes dos candidatos e partidos divulgados, cotejando-os com a totalidade dos que participaram da disputa, bem como a divulgação ou não de resultados de pesquisas. Mais uma vez, consta-se que, embora afirme mostrar todos os lados, $\mathrm{ZH}$ cobre as campanhas eleitorais pelo ângulo que lhe é mais conveniente.

Considerações finais
Os princípios normativos de $\mathrm{ZH}$ - isenção, neutralidade, independência, pluralidade - não resistem ao confronto com as suas coberturas jornalísticas e tornam-se frágeis diante das atuais condições históricas, políticas e mercado-lógicas. As contradições que envolvem o jornal da RBS são indicadores de algo estranho à natureza da imprensa, mas parecem compatíveis com a complexidade contemporânea. As ações publici-tárias de $Z H$, mesmo que em direção oposta à natureza de ambos - retratar o código normativo na prática jornalística - visam "compensar" as dissonâncias entre a retórica e a práxis. E isso sugere ação de natureza estratégica ${ }^{15}$ que possibilita ao jornal intervir, simultaneamente, nos processos político-eleitorais e resguardar seus interesses mercado-lógicos.

As (des)constituições, (dis) funções, sobreposições, misturas e até as contradições entre os três principais discursos de $Z H$ encontram eco na hibridação, marca dominante desde o final do século $\mathrm{XX}$. E os monopólios privados da mídia têm as condições para tais hibridações: matérias e anúncios veiculados, antes de serem pautados e diagramados, disputam espaços, hierarquias e poderes, sob a regência dos interesses do capital-mercado ${ }^{16}$, embora as empresas jornalísticas - $\mathrm{e}$ Zero Hora não é exceção - insistam em afirmar que são independentes, comprome-tidas com a verdade e com o interesse público.

Kucinsky (2001) observa que vem crescendo entre os jornais ${ }^{17}$ a contradição entre a natureza do jornalismo e a sua ética, inclusive com a quebra da barreira comercial/ editorial: há jornais que não se enunciam mais como a melhor fonte de informação; ao contrário, se promovem como o melhor veículo 
para os anúncios publicitários. As news to users, ou notícias para consumidores, bem como os acordos e até patrocínios de reportagens vêm desfigurando a atividade jornalística, que vai assim se aproximando da publicidade, das promoções e do próprio marketing.

Abstract

Based on hybridation processes of institutional, journalistic and advertisement discourses in the daily Zero Hora, between 1998 and 2004, considered as strategies to its political and marketing action, we lay down the foundations for future studies of discourse hybridation in mass media. One evidence of this hybridation can be found in the contradictions between the editorial guidelines and the news coverage, the news coverage and the advertisement policy. Our research is based on the complexity of modern times, it establishes a dialogue about the discourse relationship and transgressions in a mass media like Zero Hora, emphasizing the nature of its journalistic and advertisement activity and market as well as its political influence in the life of the State of Rio Grande do Sul.

Keywords: Mass Media. Disourse hybridation. Strategy.

\section{Bibliografia}

As falsas sutilezas do jornalismo: medições da cobertura da mídia mostram que a imprensa, ao contrário do que apregoa, tomou partido em São Paulo. Carta Capital, São Paulo, 27 outubro 2004, p. 31.

BAUDRILLARD, Jean. A Sociedade de Consumo. Lisboa: Edições 70, 1974.

BERGER, Christa. Campos em Confronto: A terra e o texto. Porto Alegre: Ed. da UFRGS, 1998.

BOURDIEU, Pierre. O Poder Simbólico. Rio de Janeiro: Bertrand Brasil, 2000.

BROCHAND, B. et al. Publicitor. Lisboa: Dom Quixote, 1999.

BUENO, Sérgio. Dependência de Campos de Discurso Engajado. Porto Alegre: UFRGS, 1999. Dissertação (Mestrado em Comunicação e Informação), Programa de Pós-Graduação em Comunicação e Informação, Faculdade de Biblioteconomia e Comunicação. Universidade Federal do Rio Grande do Sul, 1999.

CANCLINI, Néstor Garcia. Culturas Híbridas: Estratégias para entrar y salir de la modernidad. México: Grijalbo, 1990.CHAMPAGNE, Patrick. Formar a Opinião: 0 novo jogo político. Petrópolis: Vozes, 1996.

COELHO NETTO, José Teixeira. Moderno Pós-Moderno: Modos \& versões. São Paulo: lluminuras, [s.d.]. CONNOR, Steven. Cultura Pós-Moderna: Introdução às teorias do contemporâneo. São Paulo: Loyola,
1996.

DREYFUS, Hubert; RABINOW, Paul. Michel Foucault, Uma Trajetória Filosófica: Para além do estruturalismo e da hermenêutica. Rio de Janeiro: Forense Universitária, 1995.

ECO, Humberto. Cinco Escritos Morais. Rio de Janeiro: Record, 2001.

FAUSTO NETO, Antonio. Mortes em Derrapagem. Rio de Janeiro: Rio Fundo Ed., 1991.

FIRPO, Marcelo; PINO, Marcelo; KINDLEIN, Liziane. Campanha Publicitária "A Vida por Todos os Lados". Porto Alegre, 26 outubro 1999. Palestra proferida na disciplina Redação Publicitária I, FABICO/UFRGS.

FOUCAULT, Michel. Microfísica do Poder. Rio de Janeiro: Graal, 1979.

GRUPO RBS. Portfolio. Porto Alegre: RBS, 1997.

HARVEY, David. Condição Pós-Moderna: Uma pesquisa sobre as origens da mudança cultural. São Paulo: Loyola, 1996.

HELLER, Agnes. A Condição Política Pós-Moderna. Rio de Janeiro: Civilização Brasileira, 1998.

KOTLER, Philip. Administração de Marketing: A edição do novo milênio. São Paulo: Prentice Hall, 2000.

KUCINSKI, Bernardo. Panorama do Jornalismo Brasileiro Contemporâneo: Tendências, impasses e desafios. Porto Alegre, 24 agosto 2001. Palestra no PPGCOM/ PUCRS.

LANDOWSKI, Eric. A Sociedade Refletida. São Paulo: EDUC, 1992.

LYOTARD, Jean-François. 0 Pós-Moderno. Rio de Janeiro: José Olympio, 1993.

LONGOBARDI, Ana Carmen. A criação virou sapo. Press Advertising, Ano VI, edição 96, s/d, p. 38.

MACHADO, Maria Berenice da C. Estratégias híbridas de ação política e mercadológica: estudo dos discursos normativo, jornalístico e publicitário do jornal Zero Hora, no período 1998-2004. Porto Alegre: PUCRS, 2004. Tese (Doutorado em Comunicação Social), Pontifícia Universidade Católica do Rio Grande do Sul, 2004.

. Tomando Partido. In: HAUSSEN, Doris (org.). Mídia, Imagem e Cultura. Porto Alegre: EDIPUCRS, 2000.

MORIN, Edgar. Introdução ao Pensamento Complexo. Lisboa: Instituto Piaget, 2001.

1995. Terra-Pátria. Porto Alegre: Sulina,

MOUILLAUD, Maurice. Aos Leitores Brasileiros. In: ; PORTO, Sérgio Dayrell (org.); RODRIGUES,

Adriano Duarte et al. 0 Jornal: Da forma ao sentido. Brasília: Paralelo 15, 1997.

OLIVEIRA, Rosane. Jornalismo político. Novo Hamburgo, 22 out. 2003. Palestra proferida na Semana Acadêmica da Feevale.

ORLANDI, Eni. Análise de Discurso: Princípios e procedimentos. Campinas: Pontes, 2002.

$\mathrm{RECH}$, Marcelo. As pesquisas em seu devido lugar. Zero Hora, Porto Alegre, 15 nov. 1998, p.16. Pesquisas e Independência. Zero Hora, Porto Alegre, 3 out. 1999, p.12.

RUBIM, Antonio Albino. Comunicação e Política. São 
Paulo: Hacker, 2000.

RÜDIGER, Francisco. Tendências do Jornalismo. Porto Alegre: Ed. da Universidade/UFRGS, 1998.

SADER, Emir. Monopólio privado da mídia é obstáculo à democracia. Disponível <www.agenciacartamaior. uol.com.br>, acesso 25 de outubro de 2004.

SAMPAIO, Rafael. Propaganda de A a Z: Como usar a propaganda para construir marcas e empresas de sucesso. Rio de Janeiro: Campus, 1997.

SAMPREDRO, Victor; RONCERA, María. Información Gráfica Electoral: Info-propaganda y guerra de estrellas. TXT - Textos de Cultura e Comunicação, Salvador, n.40, dez. 1999, p.125-127.

SANT'ANNA, Armando. Propaganda: Teoria, técnica e prática. São Paulo: Pioneira, 1996.

SARTORI, Giovanni. A Política. Brasília: Ed. da UnB, 1997.

SCHIRMER, Lauro. RBS: Da voz do poste à multimídia. Porto Alegre: L\&PM, 2002.

WEBER, Maria Helena. Comunicação e Espetáculos da Política. Porto Alegre: Ed. Universidade/UFRGS, 2000a.

Consumo de Paixões e Poderes Nacionais:
Hibridação e permanência em espetáculos políticosmediáticos. Rio de Janeiro: UFRJ, 1999. Tese (Doutorado em Comunicação e Cultura), Universidade Federal do Rio de Janeiro, 1999.

Hibridação de Verdades Políticas e Mediáticas. Porto Alegre: FAMECOS PUCRS/ COMPÓS - Associação Nacional dos Programas de Pós-graduação em Comunicação, maio 2000b. CD. (Disponivel em <http://www.intexto.ufrgs.br/v6n6/av6n6a4.html>, acesso em 07/06/04).

WEISSHEIMER, Marco Aurélio. Reflexões sobre a mídia. Disponível <www.agenciacartamaior.uol.com. br>, acesso 23 nov. 2004.

ZERO HORA. Caderno 30 Anos: A notícia transformada em História. Porto Alegre, 4 maio 1994. 140p. ZERO HORA. Manual de Ética, Redação e Estilo. Porto Alegre: RBS/LP\&M, 1994.

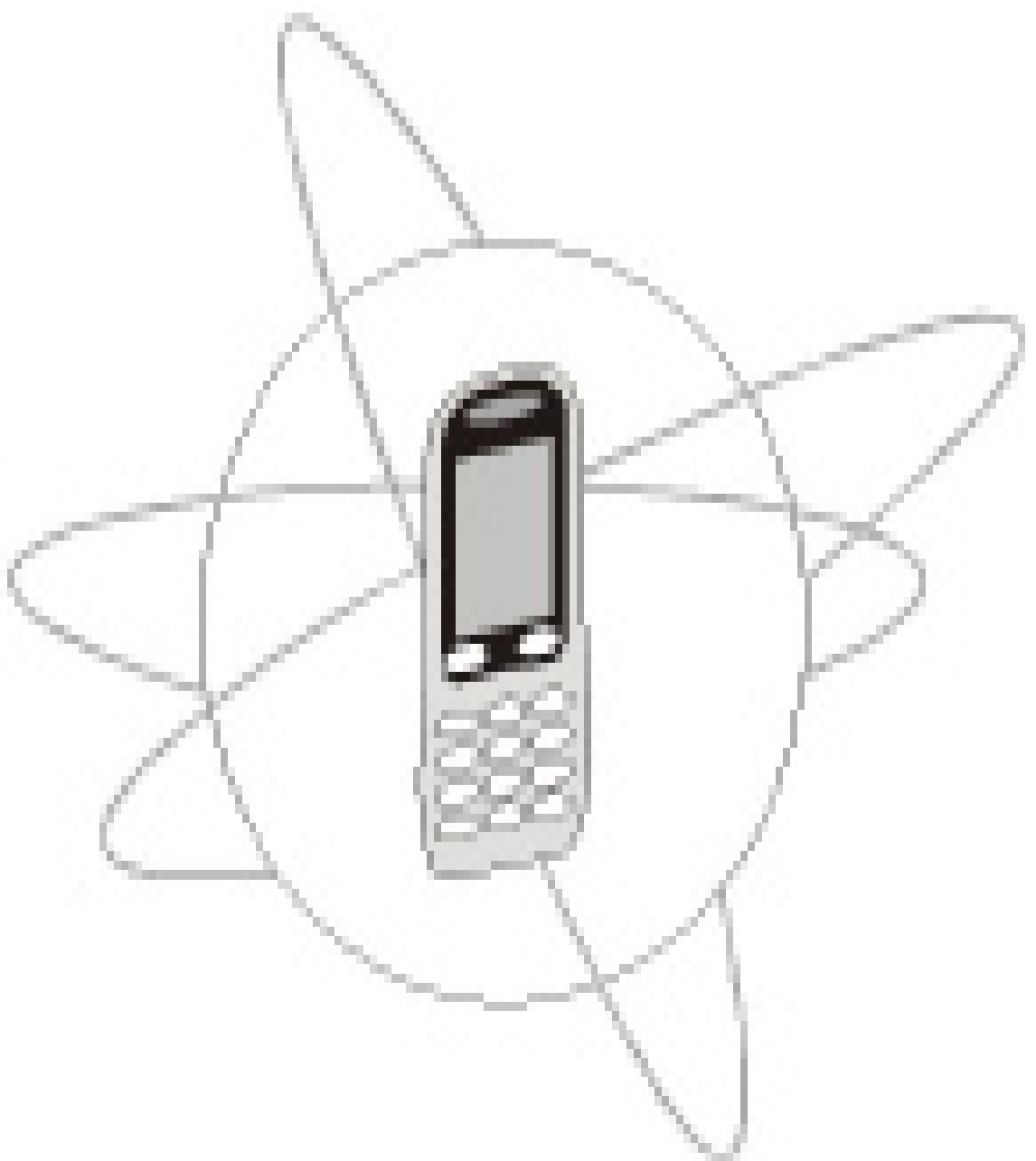

Data do recebimento: 03/06/2007

Data do aceite: 14/08/2007

Maria Berenice da Costa Machado. Hibridações discursivas: Estratégias políticas e mercadológicas dos veículos de comunicação de massa. Comunicação e Informação, V 10, nº 1: pág 52 - 62 - jan/jun. 2007. 